\title{
The Perceptions of Parents and Teachers about the Classroom Environment and
}

\section{Morality}

\author{
Dr. Afsheen Salahuddin*
}

\begin{abstract}
The basic objective of this study was to explore the issues of morality in the classroom environment and to look for the ways to teach moral values to the students during their classes. This small-scale study has tried to provide some solutions to this issue. The present study has adopted a qualitative paradigm for the in-depth analyses of the issues regarding morality and classroom education. The study includes semi structured interviews taken from ten parents whose children are studying at the university level. Moreover, ten university teachers were also interviewed to know about their views regarding the issue of how to teach moral values to the students in the classroom setting along with teaching. The interviewees were chosen through purposive sampling technique. The interviews were semi structured so that real views of the teachers and parents could be explored and also to make them feel relaxed. The interview consisted of five open ended questions. The interviews were recorded and later transcribed and then they were analysed by utilising the thematic analysis technique. The major themes which emerged after the analysis were that first of all, teacher should be a role model practicing the moral values himself/herself. Another theme was bridging the gap between parents and children, also enhancing friendliness among the teachers and their students so that students could be taught how to observe certain ethics and values in the classroom settings in an informal way like showing some videos or discussing some news which highlight some moral issues. Another theme was to develop a model based on moral education which should be incorporated into the curriculum of the educational institutes. The study provided some effective solutions which if incorporated in the classroom teaching can be helpful in solving the issue of morality among the students.
\end{abstract}

Keywords: Moral education, morality, moral values.

This Article can be cited as:

Salahuddin A., (2020). The Perceptions of Parents and Teachers about the Classroom Environment and Morality, Journal of Arts and Social Sciences. VII (2), 43-51.

\footnotetext{
* Correspondence concerning this article should be addressed to Dr. Afsheen Salahuddin, Adjunct Faculty at Beaconhouse National University, afsheensalahuddin50@gmail.com, Afsheen.salahuddin@bnu.edu.pk.
} 


\section{Introduction}

It has always been emphasized to teach moral values to the students in the classroom. The emergence of the social media and the access and exposure to a lot of different social sites have influenced the students morally all over the world. Every country has its own sets of moral and religious values which need to be passed on to the new generation. The problem arises when the impact of the outside world becomes greater than the training at home and in the classrooms. Both parents and teachers realise the gravity of situation but how to solve the issue is a big question here.

"Education is the sum of the reflective efforts by which we aid nature in the development of the physical, intellectual, and moral faculties of man, in view of his perfection, his happiness, and his social destination." (Sutton 1892). Shah et al., (2012) elaborates the same point by explaining that schools and educational institutes are the places for developing the interest of learning in the students. The schools specially are responsible for the moral development of children in their early years of life. Beacham (1980) (cited in Shah et al., 2012) states that the students who study in a school where the teachers do not have developed moral personalities develop a disliking for their schools and eventually leave their schools. Brophy (2004) (as cited in Shah et al., 2012) further elaborates the same point made by Beacham that a fearful atmosphere at school will do no good to the moral development of their students. These points show that the schools and other educational institutes are responsible for the character building of the students.

Shah et al., (2012) conducted a qualitative study in four different educational institutes of Gilgit Baltistan, Pakistan. They conducted semi structured interviews from the students of these schools. Twenty-four students, six from each school were selected for the interview. The researchers wanted to explore the reason that why students feel that school is an uninteresting place and they do not attend the school regularly. The dropout rate of the schools increased rapidly and hence this research study was conducted to find out the reason. The reason turned out to be unethical and impolite behaviour of the teachers. The study concluded that the moral and ethical development of students is directly proportional to the moral and ethical features of their teacher's personalities.

Christophel (1990) (cited in Shah et al., 2012), further states that the teachers who use threats with their students also tarnish their personalities and their students develop a certain disliking for their institutes.

As elaborated by Sutton, "providing moral education to the students has always been a dream that has not come true till now despite doing so much effort. The teachers always come to the classes with a well-planned lesson but no planning is done for the moral development of the students. Children are born imitators but this natural instinct is never utilized to teach moral values to the students. Moreover, planning and implementing a proper Moral Model is also a very difficult thing" Wilson, (2000) Also states that devising a proper methodology for teaching moral values to the students is a very complicated thing. Moreover, he also debates on the word "moral" itself and states that this word may have different implications in different cultures or societies." According to some researchers (Evans, 2006, Covell \& Howe, 2001) character development is a societal problem in which we all need to play a role for the younger generation.

\section{Objective of the Study}

To explore the ways to teach moral values to the students within a classroom setting by taking insights from parents and teachers.

\section{Research Questions}

- What are the suggestions of parents for the teachers for teaching moral values in a classroom setting?

- What are the suggestions of teachers for teaching moral values in a classroom setting?

\section{Research Sub Questions}

- Do the teachers already have some knowledge of what exactly is moral education? 
- Are the parents aware of how important is the moral education in the classroom setting?

- Is a formal character building or moral education program necessary to be designed and implemented in the institutes?

\section{Interview Questions}

After a general observation of teachers and students the following interview questions were developed by the researcher to be asked from both teachers and the parents.

- Do you feel that your children or your students feel safe and at ease at the university? Do you feel that the students care for each other in school and respect each other also? Please elaborate your reply. (The probing questions included asking for some examples as told by their children)

- How important is the role of a teacher in inculcating the moral values in students? (The probing questions included asking the parents about some examples of the teachers (without taking their names) which have been told to them by their children)

- How can both teachers and parents work together for developing the moral character of their students? (The probing questions included asking for some practical suggestions)

- What are some suggestions you would like to propose for how to teach the moral education in the classroom setting? (The probing questions included asking for some model which they knew about or which they have observed during their university lives)

- Is a formal model of teaching moral education should be developed by the educational institutes for the development of moral values in students? (The probing questions included asking for some suggestions on how to develop a model)

\section{Sample}

The interviewees were chosen through purposive sampling technique. Ten parents whose children were study at the University level (Private sector) were chosen along with ten University teachers the research was qualitative nature and a thorough investigation was required therefore, the sample size was kept small as the in-depth analysis requires a lot of time.

\section{Methodology and Research tool}

Choosing a proper research paradigm and research methodology is crucial to any research that is carried out. Guba \& Lincoln, (1994, p. 107) have elaborated, "a paradigm is every person's individual view of how he perceives this world. Mertens (2010) states, constructivism is the belief that the people have their own interpretation of the realities of this world and that there can never be one single reality as each individual is perceiving the world according to his or her experiences. Pragmatism adopts that is in between the positivism and the constructivism. Positivists and post-positivists utilize the quantitative approach while the constructivists by and large adopt the qualitative methodology.

The present study has adopted a constructivist paradigm for the in-depth analyses of the issues regarding morality and classroom education. It is a qualitative study. The researcher wanted to see that how the teachers and the parents interpret the moral development of their children according to their personal experiences. Therefore, this study was kept qualitative for the purpose of extracting real views of the teachers and parents involved in the study. The interview questions conducted were kept simple and flexible and the interviewers' comfort was given the top priority.

\section{Research Tool}

The study includes semi structured interviews taken from ten parents whose children are studying at the university level as well as from ten university teachers. The interviews were semi structured so that real views of the teachers and parents could be explored and also to make them feel relaxed. The interview consisted of five open ended questions. As elaborated by Drever (1995), Interviewing is the common technique which is utilized in small scale studies. The interviewer selects some major issues to be asked and arranges some main queries to be asked. The questions are kept flexible as they can be modified according to the response of the interviewer. This technique is most 
suitable for small case studies but is not appropriate for a large sample size. This technique is utilized for an intensive study of an issue. This technique was utilized in the present study as this also has a small sample size and also because in-depth analysis was required.

According to Bernard (1988), semi structured interviews are conducted in a scenario where you have only one or very less chance of meeting someone. (cited in Cohen,2006)

Cohen (2006) states, while taking a semi structured interview, audio or video recording is preferred as it becomes difficult for the researcher to jot down notes as well also talk to the interviewee. Usually during such an interview, the discussions gets diverged from the main topic so it is better to record the interview. The present study had also audio recorded the interviews so that each and everything stated by the respondents is recorded and nothing is missed out.

Ayers (2008) has explained that the semi structured interview technique is used in the qualitative studies where the researcher has a control over the questions being asked and the researcher may modify questions according to the answers given by the interviewee.

The study presented here has utilized the semi structured interviews while keeping all these points in mind. The questions were asked and then modified according to the interviewees' responses.

\section{Data Analysis}

The interviews were audio recorded after the interviewer's consent was taken. The interviews were later transcribed and then they were analysed by utilising the thematic analysis technique. The researcher read each interview at least 3 times in different sittings for a better understanding about the interviewers' views. At first stage interviews were transcribed to have written record of the raw data. After the transcription of all the interviews the researcher scanned the whole verbatim account. The researcher highlighted the relevant points to the research questions. Later on the researcher allotted the initial codes to those relevant points which further lead to axial codes. Researcher emerged some major as well as sub themes from the data.

Saldaña (2015) states that coding sometimes become crucial for the qualitative research methodology. Coding is not a precise scientific thing it is an interpretive act which can summarize, distil or even reduce data if not utilized appropriately. Coding for patterns is also utilized in qualitative research. Patterns are the repetitive actions or words which appear during the data analysis process. Patterns become an evidence of our findings. Sometimes we find patterns which are the common views of different people while at other times we find commonality in differences as well like someone might state that school life was boring while the other person might recall that as the boring period of their lives. Coding for patterns has been done in the present study.

\section{Results Major Themes}

The major themes which emerged after the interviews taken from both the teachers and parents after the initial coding are the following:

(Note that the teachers were given the pseudonyms of T1, T2... T10 and Parents were given the pseudonyms P1, P2...P10) on for the purpose of confidentiality.

\section{Issues at school}

Out of ten parents six (P1, P4, P5, P7, P8 and P9) of them stated that their children sometimes have issues at the university as they are not treated with respect by the other class fellows and also by their teachers. Four teachers (T1, T3, T7 and T9) stated that students come to them with such issues like being bullied and not respected. One of the parents $(\mathrm{P}, 3)$ said, "Sometimes when my son comes home from school, he seems very exhausted and upset. My son often narrates that he was bullied by the school fellows and he feels insulted. "Some of the teachers also stated that, "It's true that some students bully each other and even use abusive language and we try to teach them moral values and also have counselling sessions with the students who bully each other. The students who are being bullied are also provided counselling. 
Teachers told the researcher that they have a psychiatrist also at their institute for the problematic students and also for those who are bullied. The teachers said that, "Sometimes it becomes difficult to handle a certain situation and then we have to take our students to have sessions with our psychiatrist but at times students do not want to go and at other times parents do not approve of that."

Loubser (1971), has elaborated that the organization structure of the school as well as the authorities of the educational institutes play a crucial role for teaching moral values to their students. Therefore, the educational institutes' role can never be ignored in this context.

\section{Formal Model of Education}

All the parents and the teachers believe that there should be a formal model of moral education in every educational institute. One of the parents said, "If every student and teacher knows that they have to follow a certain code of ethics then a lot of issues regarding the immoral behaviour of students can be resolved. "Another parent stated, "The teachers should also be provided with a certain code of ethics to follow while dealing with the students. "They added, "Sometimes even the teacher is disrespectful with the students which is a very unhealthy practice."

Wilson et.al (1967) (cited in Sullivan et.al. 1971), explains that, there have always been efforts all around the world to form and implement a formal model of moral education like in England Farmington Trust research unit is involved in the formation of some moral education programs for schools.

\section{Teacher as a Role Model}

All the parents suggested that the Teacher should be a role model practicing the moral values himself/herself. Teachers were of the same view that if they themselves become a role model then students' character building can be assured. This is in line with what Sutton stated earlier.

Parents said, "If the teachers themselves will not present a role model to be followed the how the children are going to get an idea about moral values and ethics."

One of the teachers (T3) said, "As a teacher I always try to be a role model for my students to follow by showing tolerance to some of the students who misbehave and also by talking to my students with respect."

\section{Bridging the Gap between Students and Teachers}

The teachers were of the same view that the gap between parents and children should be reduced and a limited friendliness among the teachers and their students should be present.

Teachers also shared the same views. One of the teachers (T4) said, "I always have to be friendly with my students so that they may share their issues with me and then I may guide them what is right and what is wrong. "Another teacher (T5) said, "The teachers of the past were quite strict but we cannot be like them. We need to be more friendly otherwise students do not want to listen to us."

Loubser (1971) has stated that a student's moral development depends on the quality of student's teacher interaction or relationship. This further strengthens the fact that the gap between teachers and students should be reduced so that the students can interact more with their teacher and learn moral values as well through the guidance provided by their teacher.

\section{Bridging the Gap between Parents and their Children}

All the parents were of the view that with the ongoing rapid changes taking place in the world, they have to be friendlier with their children. One of the parents sated that " "Times have changed now, we were always afraid of our parents but now we need to be more friendly with our children because we feel that if we maintain distance with our children they may become depressed. We have to teach them ethics and morality in a friendly manner." 
Gauthier (1971) has stated that interaction is the key to teaching moral values either verbal interaction or non-verbal interaction. This shows that the interaction of children with their parents can play a crucial role in their moral development as they spend a lot of time with at home and a healthy interaction with their parents can lead to better morally developed individuals.

\section{Parents' Role in Supporting the Educational Institute}

Although the present research study mainly focussed on the teaching of moral values in a classroom settings but during interviews many teachers(T2,T4,T5,T6 and T7) also suggested and stressed upon the students' parents ' role in the moral training of their children.(Question No:4) One of the teacher stated that,

"There are times when the parents are not supportive when the teacher is trying to teach moral values in the classroom and has a firm strategy. Parents need to understand that students should be taught at home to respect their teachers. Moreover, parents should not unnecessarily interfere in school's policies as long as they are beneficial and they should cooperate with the teachers."

These things if acted upon or implemented will enable the teachers to teach their students how to observe certain ethics and values in the classroom settings in an informal way like showing some videos or discussing some news which highlights some moral issues

\section{Results Sub Themes}

The first major theme "Issues at school" further led to the following subthemes:

- The students should be taught respect, care, integrity, responsibility and perseverance through short videos or movie clips.

- Bullying should be taken very seriously and the students should be fined who bully other students.

- The teacher may narrate any short stories or incidents based on moral values and discuss them with the students.

- There should be a psychiatrist available in every educational institute to help students.

- Students who misbehave in the class should be provided with counselling sessions by the teachers also.

The second major theme "formal model of education" further led to the following subthemes:

- Character building should be incorporated in the curriculum. The guidelines should be provided to the teachers and parents.

- Character building should include teaching the students how to talk to each other with respect, never to lie and be honest with each other.

- Each student should be provided with a character certificate on monthly basis to encourage other students. This practice will inculcate a healthy atmosphere and every student will try to get the certificate by following moral rules.

- The moral education model should also comprise of practical demonstration like respecting the junior staff at the educational institutes.

- Model for moral education should also be shared with the parents and their suggestions should also be taken into consideration.

The third major theme "teacher as a role model" led to these sub-themes:

- Teachers should present themselves as role models by respecting students and showing them care.

- Teachers should be provided with resources like books and access to videos showing some moral lessons. Sometimes teachers do not have access to resources and they cannot do justice with their teaching practice. If teachers are provided with certain facilities like access to internet and projectors then they may show their students certain movies teaching some moral values. 
- Some current moral issues can also be shown on the internet by the teachers and discussed with the students.

- Teachers should share their personal experiences of doing something good with the students and then they can ask the students to do something good every day and then share that in the class with everyone like helping someone in crossing the road and so on.

- The teachers should also teach their students the respect of elders and their parents by providing their own personal examples.

The fourth major theme, "bridging the gap between teachers and students" further led to the following sub-themes:

- Teachers should be friendly with the students but of course within a certain limit. They should always talk to the students about their issues and problems and provide solutions to their students as well.

- A certain time should be available in the classroom when the students can share any incident or anything they want to say or talk about.

- Teacher should make sure that students feel that their teacher is easily approachable and they can share any issue with her.

- Teacher should assure the students that she will never be harsh with them and she will listen to them with patience if they have committed some mistake.

- Teacher should have to be patient with the students so that they develop a bond of mutual trust with their teacher and only then they will listen to her and talk to her.

The fifth major theme "role of parents in supporting the educational institutes" led to the following sub-themes:

- Parents should teach their children to trust their teachers and respect them.

- Parents should make sure that their children are following the guidelines provided by their teachers for teaching moral values and that their children realise that these moral values are important.

- Parents should always cooperate with their children's educational institute's authorities.

- Parents should provide their contact to the universities authorities so that they may be able to keep track of their children's academic as well as moral development.

- Parents should allow the educational institutes authorities to penalize their children with their consent like fining them if they do not follow certain moral guidelines at their university.

The sixth major theme, "bridging the gap between parents and their children also developed the following sub-themes:

- Parents should daily talk to their children about their activities at their universities.

- Parents should make their children feel that they will understand them and listen to them with patience if they have committed a mistake and they should guide them politely about the moral values.

- Parents should be available for their children all the time to listen to their problems and guide them according to the code of ethics.

- Parents should be tolerant with their children and they should guide their children whenever they need without losing their temper.

- Parents should understand that the children take time in learning and understanding certain moral issues.

\section{Limitations}

Like all subjective studies, this study had a few restrictions. The findings of this study cannot be employed due to small sample as it was drawn from only $10 \mathrm{In}$-Service teachers and ten parents. These findings could not speak to the standpoints of all Universities in Punjab. 


\section{Conclusion}

Both parents and teachers were of the view that they need to work together for the character building of the students. The teacher or the parents alone cannot work in isolation for the moral upbringing of the younger generation. The study showed that both parents and teachers showed a great concern about the moral development of their students or children. A formal moral education model should be designed and implemented in the classrooms was another major point emphasized by both parents and teachers.

The teachers themselves should present themselves as role models to their students. As stated by Mc Conaughy (1914), "a teacher who never loses temper and is patient with the students always automatically inculcates and teaches moral values to students." As Woolfolk (2008) (cited in Shah et al.,) has stated that students need freedom, they want to make noise, they need to have fun. This explains that if all these factors are taken care of, it will make the students relaxed and then the moral training will be easier to be provided to them as they will be willing to listen and act also.

The issue of incorporating ethics or moral education into the curriculum had always been under discussion. Ahmed (2009) conducted a case study in a Pakistani madrasa where the Quranic education is provided to the students. He found out that the Islamic studies are taught in such a way that only factual information is provided to the students and no practical ethical lessons are taught to them. This shows that ethics or moral values had always been ignored in our country. Now in this era of rapid developments and advancements there is a dire need of a moral education model where students are practically taught moral values.

Mahmood (2012), has stated that the media can have a positive effect on our students if utilized properly at educational institutes for teaching moral values to them because the media has the power to mould the opinions of the people. He also had the similar findings as Ahmed. These findings are in line with the present research study as this case study has also lead to the conclusion that at present there is no such model for moral education present in the education institute where the research was done. Students are practically unaware of the moral values which are taught to them in books. Therefore, practical exposure to moral values should be provided to the students as part of their moral development and media usage as already mentioned can be one way for doing that.

Although each country or culture has different opinions about morality or moral values keeping in mind the Pakistani context and after extracting the teachers' and parents' views the following main amendments can help in developing moral values among the university students: Teachers can teach moral values like truth, honesty, respect for each other and perseverance through discussions or showing audio visual aids . Teacher should be the role model to be imitated by her / his students.

The formal model can be displayed in the university premises and included in their brochures or pamphlets as well:

- The moral values like truth, honesty, respect for each and perseverance should be observed by the students.

- Parents should be kept informed about their children's moral development.

- The immoral behaviour including the disrespect of the teachers or university fellows, usage of abusive language will not be tolerated and students will be fined or in extreme cases may also be suspended or expelled from the university.

- Well-mannered students will be awarded with certificates or scholarships in every semester.

- The vision and mission statements of the universities should also include the importance of moral values.

This formal model of moral education, if implemented and acted upon properly may bring a change in the society overall. 


\section{References}

Ahmed, Z. S. (2009). Madrasa education in the Pakistani context: Challenges, reforms and future directions. Peace Prints: South Asian Journal of Peace building, 2(1), 1-13.

Ayres, L. (2008). Semi-structured interview. The SAGE encyclopaedia of qualitative research methods, 811-813.

Beck, C., Crittenden, B., \& Sullivan, E (Eds.). (1971). Moral Education. University of Toronto Press. Retrieved from http://www.jstor.org/stable/10.3138/j.ctt15jjc29

Cohen, D., \& Crabtree, B. (2006). Qualitative research guidelines project.

Drever, E. (1995). Using Semi-Structured Interviews in Small-Scale Research. A Teacher's Guide

Gauthier, D. (1971). Moral action and moral education. In BECK C., CRITTENDEN B., \& SULLIVAN E (Eds.), Moral Education (pp. 138-146). University of Toronto Press. Retrieved from http://www.jstor.org/stable/10.3138/j.ctt15jjc29.9

Guba, E. G., \& Lincoln, Y. S. (1994). Competing Paradigms in Qualitative Research . Saldaña, J. (2015). The coding manual for qualitative researchers. Sage.

Loubser, J. (1971). The contribution of schools to moral development: A working paper in the theory of action. In BECK C., CRITTENDEN B., \& SULLIVAN E (Eds.), Moral Education (pp. 147180). University of Toronto Press. Retrieved from http://www.jstor.org/stable/10.3138/j.ctt15jjc29.10

Mahmood, A. (2012). The role of schools in building a peaceful society in Pakistan.

Mertens, D. M. (2010). Research and evaluation in education and psychology: Integrating diversity with quantitative, qualitative, and mixed methods (3rd ed.). Thousand Oaks: Sage Publications.

Shah, Z., Alam, S., \& Baig, S. (2012). The moral dimension of teaching, affectionate schools and the student drop out: The case study of a mountainous community in Pakistan. International Journal of Progressive Education, 8(2), 84.

Sutton, V. (1892). Moral Education. American Annals of the Deaf, Vol. 37 (1), pp. 34-43.

Tuff, L. (2009). Teacher perception of character education (Doctoral dissertation, Lethbridge, Alta.: University of Lethbridge, Faculty of Education, c2009).

Wilson, J. (2000). Methodology and moral education. Oxford Review of Education, 26(2), 255-262. 